\title{
Importance of Y- STR profiling in sexual assault cases with mixed DNA profile
}

\begin{abstract}
Delay in medical examination of victims in sexual assault cases may affect the DNA analysis of the samples collected from victim in sexual-assault kit. In such cases we get epithelial cells and spermatozoa of both victim and accused. In DNA analysis of such samples we get mixed STR profiles. Although differential extraction is one of the methods for differentiating the male and female DNA part but it is not always successful. In differential method, chances of loosing small amount of male fraction persist. In 100 such samples where total human DNA was $15-40 \mathrm{ng} / \mu 1$ out of which male DNA was $0.23-4.46 \mathrm{ng} / \mu 1$ in quantity, partial or missing peaks of accused were generated in mixed-autosomal STR/DNA profiles due to high amount of female fraction and low amount of male fraction in the samples. Y-STR DNA profiling of such male-female mixed swabs is done for individualizing male fraction and able to justify the small peaks in autosomal STR/DNA profiles with high discrimination power in the court of law.
\end{abstract}

Keywords: sexual assault, medical examination, vaginal swabs, Y-STR fraction
Volume 3 Issue I - 2018

\author{
Naresh Kumar,' Aanchal Maitray,' Ritika \\ Gupta,' Dhruw Sharma,' Shukla SK² \\ 'Forensic Science Laboratory, Govt of NCT of Delhi, India \\ ${ }^{2}$ Professor and Head of Amity Institute of Forensic Science, \\ Amity University, India
}

Correspondence: Naresh Kumar, Forensic Science Laboratory, Govt of NCT of Delhi, India, Email nareshkumar2982@yahoo. com

Received: February 08, 2018 | Published: February 27, 2018

\section{Introduction}

Rape is a heinous crime and is a big problem for the society. Moral education in people would play an important role to curb such incidents. It is seen that in most of the cases this crime is committed by the close relatives of the victim. Due to hesitation, or other threats matter is not reported immediately to the police and subsequently delay in medical examination occurs. The scientific evidence plays an important role in sexual assault cases. Perpetrator can be booked on the basis of the biological evidences left at the crime scene or over the body of victim. These evidences play the vital role in the reconstruction of scene of crime. ${ }^{1}$ In rape cases samples must be first tested for presence of semen otherwise it may be questioned by the defense lawyer if profile is not generated from semen or may be due to other body-fluid planted by the police. Due to fluorescent nature of semen, invisible stains can be located with the help of UV lights. In case where quantity of semen is low than after presumptive acidphosphatase test which helps to identify semen stains can be further directly processed for DNA profiling. ${ }^{2}$ Present techniques of DNA profiling are well grounded upon in forensic biological examination of samples as it can generate confirmatory results for the identity of the person. Epithelial cells found in swabs give the profile of the victim along with the profile of perpetrator; however a differential DNA extraction method from samples could be used for differentiating the male part (spermatozoa) from epithelial cells but it is not suitable in delayed medical examination where male part is already lesser in amount.

In such cases, the DNA profile generated from various samples taken from the body of the victim collected in the form of SAFE (Sexual Assault Forensic Examination) kit taken in medical examination may easily used to link the accused to the crime. Y-STR DNA profiling may be done in vasectomies or azoospermic individuals without differential DNA extraction. In this study we have not used the differential method as the cases were delayed in medical examination. A rape victim wants to go the place where she feels secure and tries to clean her body and try to forget the tragic incident. ${ }^{3}$ Close relation with perpetrator may affect the reporting the case to local police and may be delayed and extend up to one month or more ${ }^{4}$ Police should show alertness for her medical examination without any delay. The samples collected at the time of her medical examination from the victim's body using the SAFE kit. Some of the swabs like vaginal, swabs and undergarments were collected. Clothes are the good source of DNA for long duration preservation of semen stains. ${ }^{5}$ Quantity difference in male and female fraction affects the peaks of male fraction comparative to the female fraction. Size of peaks of female fraction was much higher than male part due to small quantity of spermatozoa in mixed profile. STR techniques are first to be used for mix samples especially in sexual assault cases as it is very informative and easy for interpretation. In such cases Y-STR loci have been investigated in forensic science for identification of male fraction. ${ }^{6}$ This technology of Y STR is helpful to detect the male fraction in male female mixed biological material. The application of Y STR has been accepted by International society of Forensic Genetics. $^{7}$

\section{Materials and methods}

During the medical examination or at the time of recording the statement of rape victim, samples were collected by the police and deposited in the laboratory for DNA analysis. Samples were stored at $4^{\circ} \mathrm{C}$ as per standard protocol to reduce the levels of degradation. Samples were examined after 10 to 20 days of receiving in the laboratory as per pendency of cases. Total 100 such samples where human semen was found, were taken for mixed DNA profiles and Y-STR profiles. The presence of semen was confirmed by Acid phosphatase test and Microscopy of spermatozoa in the samples. The presence of spermatozoa and quantity of DNA is affected by environmental factors and cloth texture of sample like garments. ${ }^{8}$ The dye/colour of cloth may inhibit the process of DNA amplification. 


\section{DNA extraction}

The mix samples after identification of semen by acid phosphatase test and presence of spermatozoa from vaginal/cervical swabs and underwear along with washing from vagina were taken for organic extraction ${ }^{9}$ as per their protocol. The vaginal swabs taken on the cotton swabs or any other sample like undergarment etc. cut into small pieces and put in microcetrifuge tube $(1.5 \mathrm{ml})$. Sample contains both vaginal epithelial cells and spermatozoa. Samples were added $500 \mu \mathrm{l}$ forensic buffer, $50 \mu \mathrm{l}$ sodium dodecyl sulphate $(20 \%), 20 \mu \mathrm{l}$ Proteinase-K $(20 \mathrm{mg} / \mathrm{ml})$ and $10 \mu 1$ ditheothreitol $(.1 \mathrm{M})$ to digest the cells. Phenol chloroform and iso-amyl alcohol were added to samples in the ratio of 25:24:1 to remove the protein material and contaminants. Precipitation of DNA from samples was done with sodium acetate and isopropanol and further washed with the alcohol. The purpose of this method was to extract the DNA from spermatozoa along with the epithelial cells of the victim. Use of vaginal wash for DNA profiling is better source as there is no contamination or fungal growth. The inhibitors are major problem in PCR analysis in the samples like jeans pant or any other garments. The inhibitors include (i) binding of the inhibitor to the polymerase (ii) interaction of DNA with the inhibitor and (iii) interaction with the polymerase during primer extension. ${ }^{10}$ Inhibitors exerts their effect by interaction with DNA. A number of methods have been developed to improve PCR amplification in the presence of inhibition. ${ }^{11}$ One of the important methods is the use of Qiagen Investigator Kits as this technique is helpful to wash the dye of jeans pants to avoid inhibition silica-based column provided by Qiagen. ${ }^{12}$

\section{Quantification}

After completion of isolation, DNA samples were taken for quantification as it is important part of DNA profiling and international protocol do not allow profiling without quantitation of DNA. Concentration of male DNA isolated from each sample was measured by quantification method by using Quantifiler Duo Kit (Applied Bio system) on the Real-Time 7500 PCR instrument. ${ }^{13}$ This kit contains Taq-Man, Human male specific sex determining region $\mathrm{Y}$ and Internal positive control. This technique is very helpful in sexual assault cases to ascertain the quantity of male DNA in the sample and further to know the inhibition in the sample (Figure 1). Quantitation standards were used to quantify the DNA samples. Total volume of sample and kit was $25 \mu \mathrm{l}$ (Reaction mix $12.5 \mu 1$, Primer10.5 $\mu 1$ and sample $2 \mu 1$ ). STR gives more information and easy to use in forensic cases. In the case where autosomal STR fails to detect some peaks and give poor peaks of male fraction comparative to female fraction peaks than it's necessary to go for Y-STR. ${ }^{14}$ Y-STR will be done if the presence of male DNA is confirmed after quantitation in RT-PCR. Vaginal washing taken in sexual assault cases had a higher percentage of male DNA than other swabs. ${ }^{15}$ After the quantifying the DNA, the samples were diluted and amplified on conventional PCR for 28 cycles using Identifier plus kit contains, reaction mix $10 \mu 1$, primer $5 \mu 1$ and sample 1 nanogram and analyzed on the Gene Sequence 3500xl for the DNA profiling as per the protocol of applied Bio systems. The volume $5 \mu 1$ denatured DNA was run on Gene Sequencer.
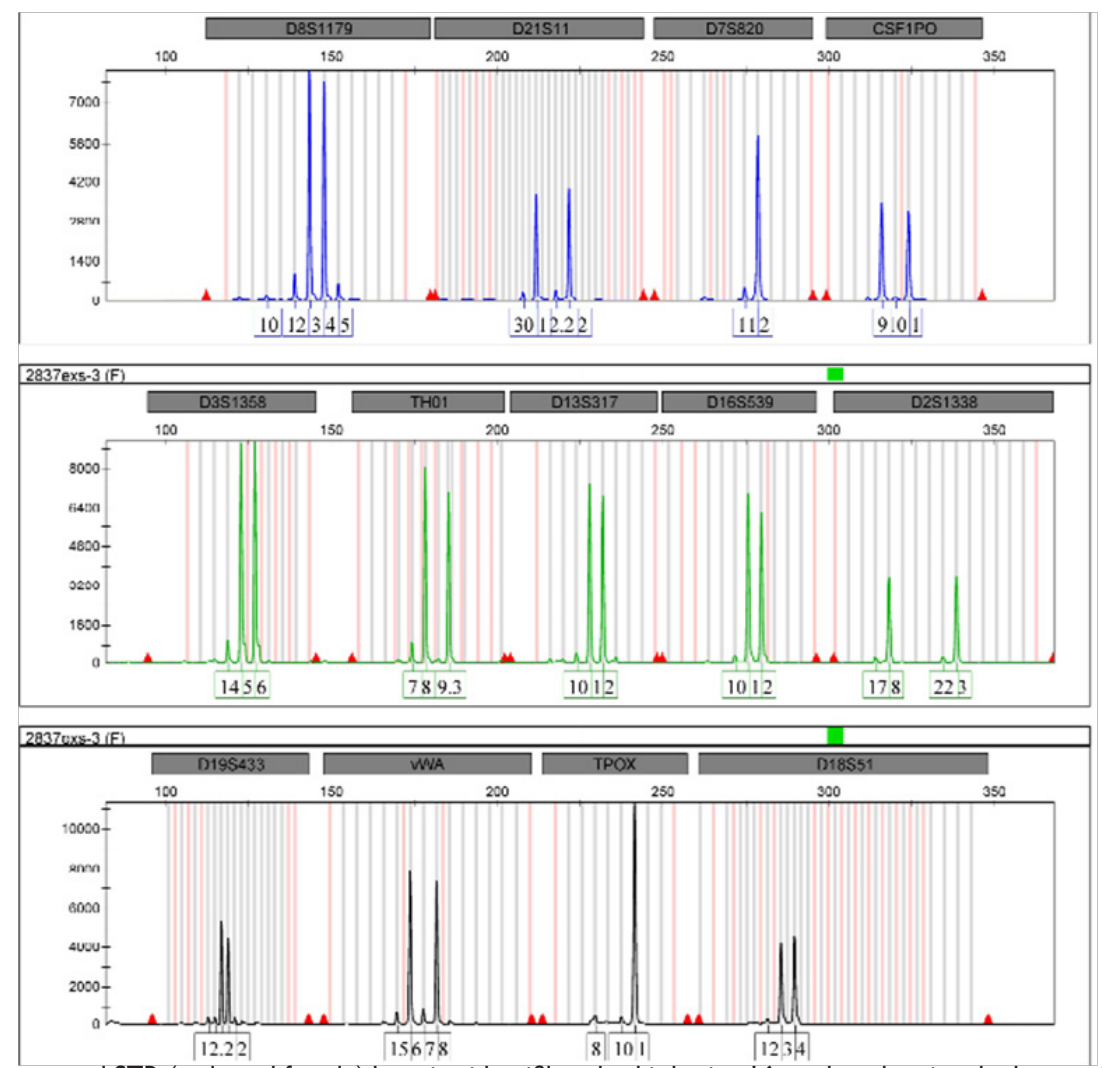

Figure I A mixed Profile in Autosomal STR (male and female) by using identifiler plus kit having 16 marker showing the low peaks of male, due to low quantity of male DNA and high peaks due to high quantity of female DNA (victim) Example Marker D2SI338 showing the male fraction peaks 17 and 22 while 18 and 23 of female fraction. 


\section{Results and discussion}

This study shows that detection of semen and further mixed DNA profile was obtained from the sample of vaginal swabs including washing of vagina and garments. Profiles generated from the mixed DNA shows that as the amount of male DNA decrease the peaks of male profile will also decrease (Figure 1). In the case where female DNA is 5 times or more than male DNA, the peaks of male fraction will be much lesser than the female fraction but visible. The ratio of female and more than 20 times to the male DNA than the peaks of male samples will be either very small or not visible in the DNA profile (Figure 2). The peaks of male fraction will not be visible if the ratio of female and male increased above 20:1 and proper DNA profile cannot be generated due to less male DNA than the female DNA (Figure 3). In such samples Y-STR can help to conclude the result. Hence it could be stated that as the medical examination delays, male fraction will also reduced and it will express in DNA profiling. Resultantly the peaks of male fraction will be less or will not be generated due to high quantity of female fraction. A positive result can be made only with combined profiling of autosomal STR and Y-STR.
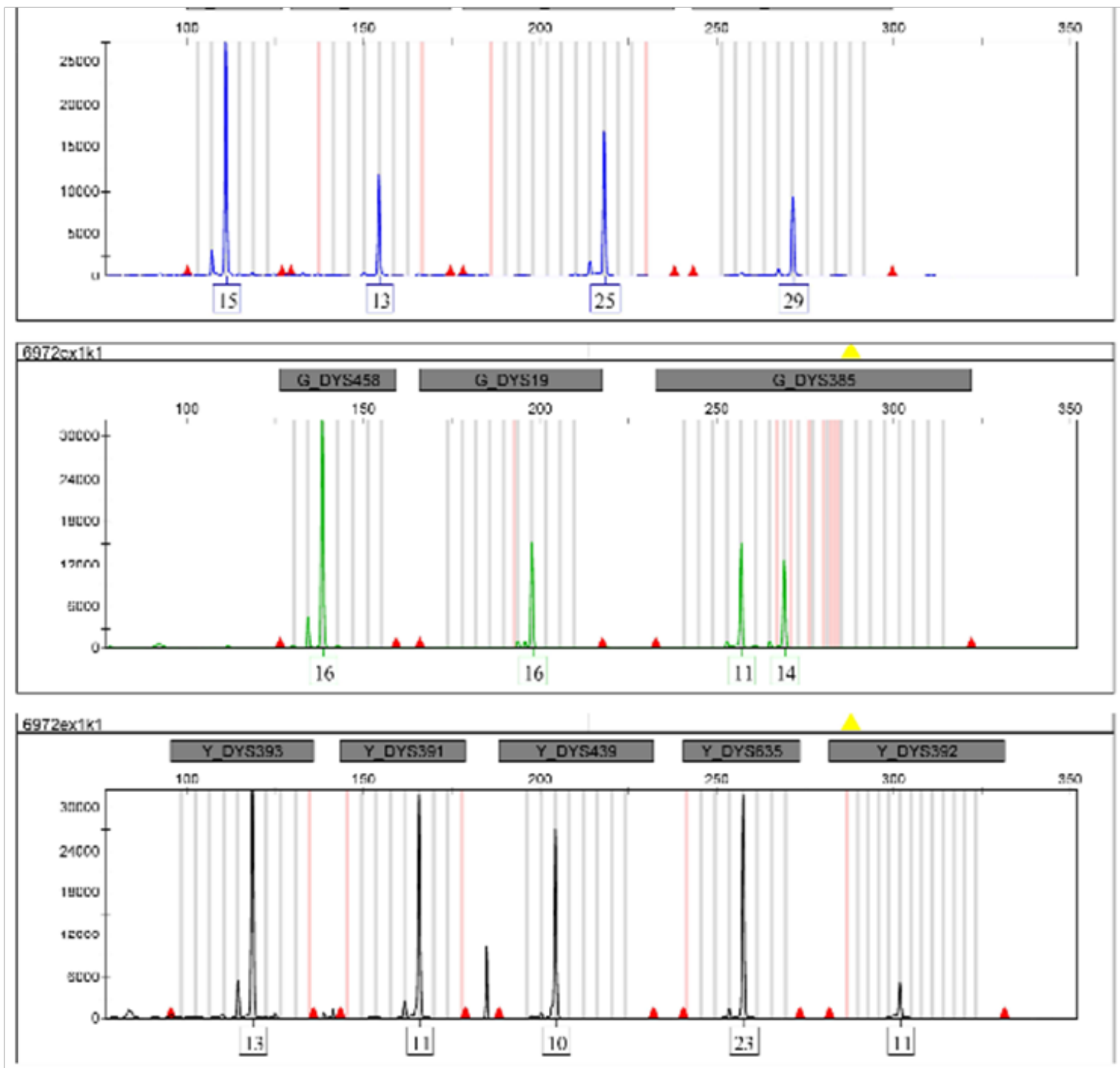

Figure 2 A Profile of Y- STR using Y filer kit showing the peaks of male DNA in mixed sample.

\section{Conclusion}

The quantitation of sample is necessary to know the male and female fraction in the isolated DNA. Without quantification of DNA sample expert is not able to justify the low peaks of male profile. Higher concentration of female fraction will give the big size peaks in mixed sample and low or no peaks of male profile. The result of such sexual assault cases can be concluded on the bases of combined analysis of autosomal and Y STR. The Quantifiler duo kit is helpful to know the ratio of male and female DNA. From this study it is concluded that quantitation, ratio of male female DNA and further profiling by autosomal and Y-STR is the best way to conclude the result in mixed DNA. If any of steps is not followed by the expert, it may fatal to the case in the court. 

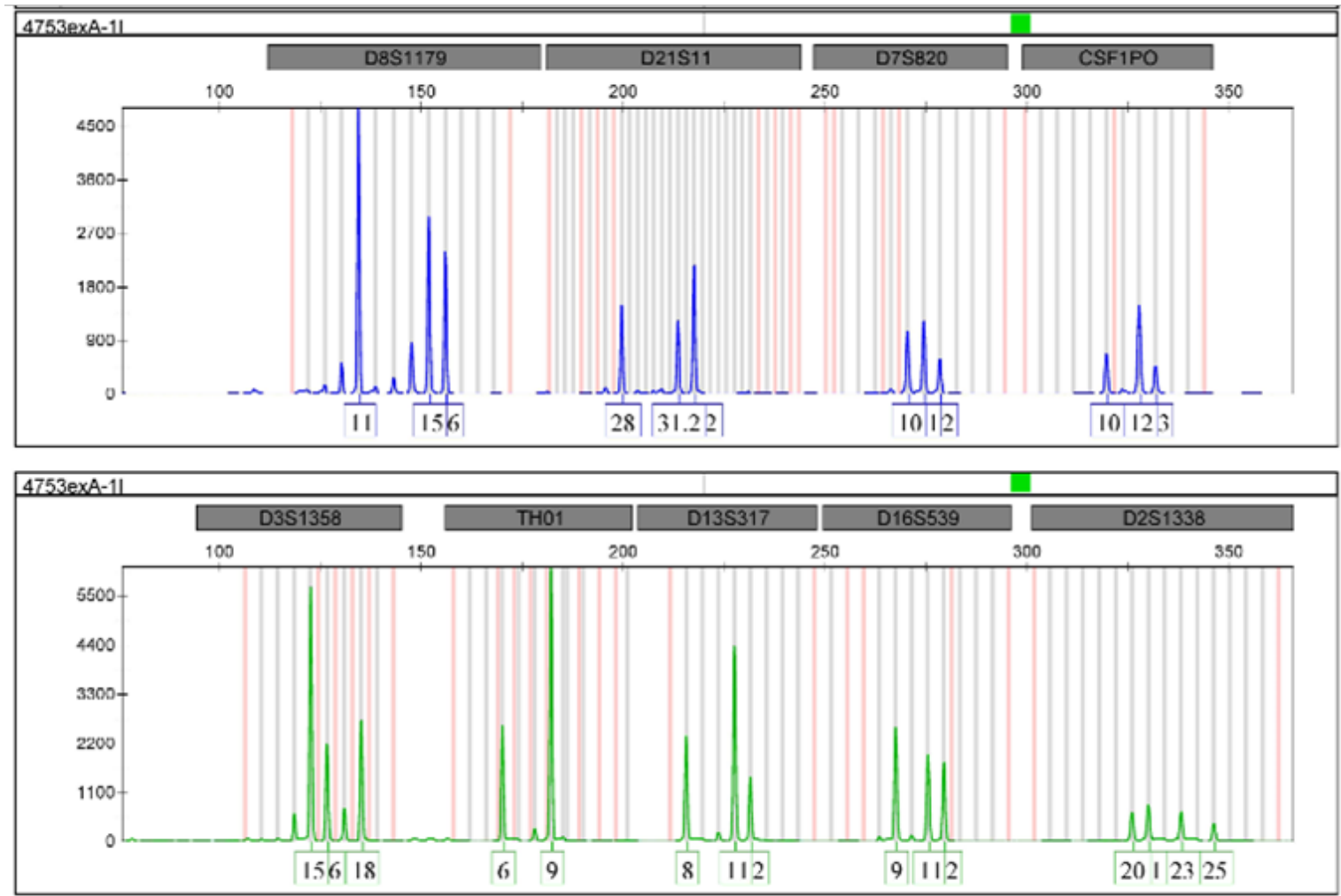

Figure 3 Another mixed Profile in Autosomal STR (male and female) by using identifiler plus kit having 16 markers. Profile showing the low peaks of male DNA and high peaks of female DNA (victim) Example. Marker D2SI338 showing the male fraction peaks 21 and 23 while 20 and 25 of female fraction but ratio of male female is better than previous profile.

\section{Acknowledgment}

None.

\section{Conflict of interest}

The authors declare no conflict of interest

\section{References}

1. Green WS PJG. Sexual assualt and semen persistance. Enclopaedia of Forensic Science. 2000;3:1016-1018.

2. Lewis J BACALB. Improved detection of semen by use of acid Phosphatise testing. Sci Justice. 2013;53(4):385-394.

3. President DNA Initiative OotVAWDUDoJ. A national protocol for sexual assualt medical forensic examination: adult/adolscents. 2004.

4. Smith DW1, Letourneau EJ, Saunders BE, et al. Delay in disclosure of childhood rape:result from national survey. Child abuse negl. 2000;24(2):273-287.

5. Kobus HJ1, Silenieks E, Scharnberg J. Improving the effectiveness of flourescence for detection of semen stains on fabrics. Indian Journal of Forensic Science. 2002;47(4):819-823.

6. Jobling MA, Pandya A, Tyler Smith C. Y chromosome in forensic analysis and paternity testing. Int J Leg Med. 1997;110(3):118-124.

7. Gill P1, Brenner C, Brinkmann B, et al. DNA commission of Internationa Society of Forensic Genetics: recommendations on forensic analysis using Y chromosome STRs. Forensic Sci Int. 2001;124(1):5-10.
8. Lay Hong Seah, Mohd Izuan Othman, Primulapathi Jaya, et al. DNA profiling on fabrics: an situ method. International Congress Series. 2004;1261:565-567.

9. Norah Rudin, Keith Inman. An Introduction to Forensic DNA Analysis. 2nd ed. CRC press; 2001: e312.

10. Morera D. Efficient removal of PCR inhibitors using agarose-embedded DNA preprations. Nucliec Acids Res. 1998;26(13):3309-3310.

11. Bourke MT, Scherczinger CA, Ladd C, et al. NaoH treatment to neutralize inhibitors of tag polymerase. J Forensic Sci. 1999;44(5):1046-1050.

12. John MB. Fundamental of Forensic DNA typing. 2nd ed. Elsevier; 2005: e668.

13. Nicklas JA, Buel E. Dovelopement of an alu-based,real-time PCR methods for quantitation human DNA in forensic samples. $J$ Forensic Sci. 2003;48(5):936-944.

14. Martin P, AC. Application of Y-STR analysis to rapes that cannot be solved by bautosomal STR. Progress in Forensic Genitics. 2000;526-528.

15. Naresh Kumar Vinita Gaur, Vijayshree Singh, et al. Studies of different clue materials for semen detection and DNA fingerprointing in sexual assualt cases. International journal of Multidiscipilinary Research and Dovelopement. 2015;2(4):286-288. 